\title{
An assessment of the factors influencing household willingness to pay for non-marketed benefit of cattle in the agro-pastoral systems of Mozambique
}

\author{
S. K. Ng'ang' ${ }^{1,2 \star}{ }^{1}$, C. Ritho ${ }^{2}$, J. Nzuma ${ }^{2}$, S. Moyo ${ }^{1}$ and M. Herrero ${ }^{1}$ \\ ${ }^{1}$ International Livestock Research Institute (ILRI), P. O. Box 30709, Nairobi, Kenya. \\ ${ }^{2}$ Department of Agricultural Economics, University of Nairobi (UoN), P. O. Box 30197, Nairobi, Kenya.
}

Accepted 9 November, 2010

\begin{abstract}
This study used Probit model to analyze factors influencing probability of household willingness to pay for non-marketed benefits (NBS) of cattle in Mozambique. The primary data from 184 agro-pastoralist households were collected using a structured questionnaire. Data collected comprised information relating to household demographic, household livelihoods and non-marketed benefits of cattle. The result showed that the probability of household willingness to pay (WTP) was influenced by both animal and household related characteristics. Animal related characteristics that had a significant influence on the probability of households WTP for NMB's of cattle included: Animal age (ANAGE), herd size (HERDSIZE) and cattle breeds (INDBRED). Household related characteristics that had significant $(p<0.05)$ influence on probability of household WTP for NMB's of cattle, comprised: Dependant ratio (DEPRAT), household size (HHS), off-farm income (OFFINC) and distance to the market (DISTMK). As expected, however, the OFFINC had a negative influence on probability of household WTP for NMB's of cattle. The study concluded that non-marketed benefits of cattle were highly valued among agropastoralist in Mabalane district and thus were willing to pay for them.
\end{abstract}

Key words: Non-marketed benefits, cattle, probit, probability, households, willingness to pay.

\section{INTRODUCTION}

In Sub-Saharan Africa (SSA), approximately $70 \%$ of the households own and depend on livestock for food and income to a varying degree (Thornton et al., 2002). Livestock are kept for the multiple benefits that they provide. They are a source of income and one of the few assets available to the poor especially women. They are also source of manure, a non-marketed benefit (NBS) that is vital in preserving soil fertility and promoting sustainable intensification in farming systems. In addition, livestock act as livelihood diversification strategy, particularly in arid and semi arid land (ASALs) which are characterized by a single cropping season per year.
In SSA, livestock account for approximately $30 \%$ of the total value of agriculture in gross domestic product (GDP) (Shackelton et al., 2001). Livestock also employs approximately $90 \%$ of the economically active population, hence a key source of livelihoods, particularly in ASALS where rainfall is less limiting (IFAD et al., 2004). Furthemore in ASALs human survivals rely more heavily on livestock unlike in areas of higher agricultural potential, since the reliance on livestock increases with decreases in rainfall (Ouma et al., 2004).

In Mozambique, livestock production accounts for $15 \%$ of the total GDP derived from agriculture (Food and 
Agriculture Organization (FAO, 2007). However, the contribution by livestock to the GDP excludes nonmarketed benefits derived from for example cattle, which in Southern Africa countries are equally valued as milk or meat (Dovie et al., 2002; Delali, 2004). The non-marketed benefits derived from cattle include: As a form of savings, payment of dowry, financing and insurance against risk (Hooton, 2000). Therefore, cattle have considerable social and cultural significance and could be the main reason that motivates agro-pastoralists to keep them (Moll et al., 2001).

Wealth defined as the accumulation of assets is a nonmarketed benefit derived from cattle and confers financial security, prestige and social status. Wealth is distinct from income, which provides the means of attaining wealth and support household current consumption and investment. Cattle directly perform both functions of income and wealth among households. As a source of wealth and income, cattle provide satisfaction in terms of numbers as well as cash value (Doran et al., 1979). Moreover as a form of savings, cattle performs financing roles particularly where banking is absent or not fully integrated in the rural areas. The financing function of cattle involves converting part of the herd income through sales to enable households meet their expenditures (Barrett et al., 2001).

Financial markets in the rural areas of Mozambique perform poorly and opportunities for risk management through formal insurance are generally absent (Bosman, 1995). Consequently, to cope with the risks, people in rural areas have to search for alternatives strategies. One risk-reducing strategies practiced by households to smooth consumption is liquidation of assets such as cattle. Cattle perform insurance roles as capital invested in herd forms a guarantee for meeting future unexpected requirements. Insurance involves maintenance of a capital stock embodied in cattle as a guarantee for offsetting shortfalls in earnings and unforeseen expenses in the future (Slingerland, 2000: Ouma et al., 2004). Therefore, cattle have considerable social and cultural significance and may be the main reason why household rears them (Moll et al., 2001).

In Gaza province of Mozambique, households adopt multiple livelihood strategies such as rearing cattle for both marketed and non-marketed benefits (Shackleton et al., 2002). However, research aimed at improving household livelihoods through cattle often targets marketed benefits while neglecting non-marketed benefits (Shackleton et al., 2001). Consequently, the economic contributions of non-marketed benefits of cattle to households' livelihood are not well understood. It therefore becomes important to undertake empirical studies that can evaluate cattle contribution to the household livelihoods.

Thus this study seeks to evaluate the contribution of cattle to the household livelihood by assessing household willingness to pay (WTP) for non-marketed benefits of cattle. These studies seek to test the hypothesis that, the probability for household WTP for non-marketed benefits of cattle is not influenced by cattle and household related characteristics.

\section{LITERATURE REVIEW}

In order to determine the value of non-marketed good and services, economists have developed several techniques broadly categorized into: Revealed preference techniques, stated preference techniques and ex-ante assessment (Dofonsou and Deboer. 2008). Revealed preference techniques rely on values inferred from people's behavior in markets which in some way are connected to the non-marketed value. Revealed preference methods measure only use value and example includes hedonic pricing (HPM) and travel cost methods (TCM). Ex-ante assessment relies on the effects of changes to an existing management regime, that is, marginal value of the relevant resource and example includes cost benefit analysis (CBA) (Campbell et al., 2003).

The HPM is used to estimate economic values for ecosystem or environmental services that directly affect market prices and is often applied to estimate variations in housing prices to reflect the value of local environmental attributes (Taylor, 2002). TCM is used in estimate the value of recreational benefits derived from an ecosystems (Parsons, 2003). The basis of the travel cost method is that time and travel expenses incurred by visitors is the "price" of accessing the site. The willingness to pay (WTP) for a site visit is then estimated from the number of trips made at different travel costs.

Stated preference methods are based on intended behavior and involve questioning people in a survey setting (Dofonsou and Deboer, 2008). Stated preference method does not rely on revealed preferences expressed via the market, hence flexible. It relies on each respondent's statement of value in a surrogate market environment and example includes Contingent Valuation Method (CVM) and contingent choice method (CM) (Bennett and Blamey, 2001). The CVM is used to estimate use and non-use economic values for a wide range of non-market goods and services, including ecosystem and environmental (Boyle, 2003b).

CVM is based on a respondent's WTP ${ }^{1}$ (or willingness to accept (WTA)) for good or service, contingent on a hypothetical scenario (Freeman, 1993). Survey questions can be either open or close ended. In open ended approach, respondents are presented with a hypothetical but plausible situation and then asked the maximum amount of money they would be willing to pay for amelioration from the status quo or the minimum amount of compensation they would be willing to accept (WTA)

\footnotetext{
${ }^{1}$ WTP is the value a farmer is willing to pay for a service and because it can indicate the limit of utility to the user, it is used as a measure of utility
} 
for deterioration from the status quo. Close ended method involves asking a respondent whether they would be WTP a specified amount for a specific good or service.

In this study CVM was utilized to assess the factors that influence households WTP for non-marketed benefits of cattle in Mozambique. CVM has sound basis in the theory of welfare economics. Welfare economics seeks to reveal whether the potential change in utility resulting from a change in an economic variable such as a commodity's price is positive (Just et al., 1982). CVM offers the potential to trace factor influencing the WTP distribution among a population of economic agents to proposed change for non-marketed benefits of cattle (Carson et al., 2000).

\section{Review of empirical studies}

In an attempt to get a better quantitative grasps of benefits derived from goats in Southwestern Nigeria. Bosman et al. (1997), used CBA to evaluate the nonmarketed benefits (financing, saving and insurance) of goats based on foregone cost perceived as benefits that could be added to the production value of goat. The objective was to measure and interpret benefits of goat keeping in a tropical farming system. The values of marketed benefits were captured by assessing both input and output resources used in system of goat farming. To avoid double counting non-marketed benefits were assessed based on the outflow as it represents part of the flock used in meeting the household's expenditure.

The Bosman et al. (1997) study concluded that although policies and measures aimed at improving livestock focuses on production and productivity, it must be realized that farmer has multiple goals. Although Bosman et al. (1997) was similar to the present study by recognizing the important contribution of non-marketed benefits of livestock to farming systems. The study did not assess the factor that influences household reliance on the non-marketed benefits of goats.

In an attempt to incorporate perception of farmer while considering socio-economic benefits of cattle Ouma et al. (2004) used CVM to estimate and compare the competitiveness among three livestock production systems. This study finding concluded that socioeconomic benefits of cattle indeed comprised approximately $20 \%$ of animal total economic value in intensive, semi intensive and extensive systems. However Ouma et al. (2004) study did not assess the factors influencing households' WTP for non-marketed benefits of cattle. Thus, the present study seek to assess factors influencing the probability for households WTP for non-marketed benefits of cattle.

\section{METHODOLOGY}

To better assess factor influencing households' dependence on non-marketed benefits of cattle, the study draw on the broader livelihood strategy literature as a framework of analysis. The livelihood approach aims to highlight the different elements that's shapes households livelihood in a community, the factors that influence them and the linkages between various factors. The approach is centered on households and their livelihoods. In this regards, the engagement of households in agro-pastoral system of cattle keeping is driven by the objective of deriving non-marketed benefits. This is an economic choice in its pursuit of making a living given resources endowment, household characteristics and exogenous factors.

\section{Conceptual framework}

Figure 1 present the basic framework of the economic value of a cattle enterprise. Non-marketed benefits of cattle, at the heart of the figure, are the focus of this study. Based on the framework, economic value of cattle enterprise comprises both marketed and non-marketed benefits. To access the marketed benefits contribution to household livelihood, marketed price are often used. However, to value non-marketed benefits of cattle, studies have shown that only methods used in valuating non-marketed benefits are more appropriate (Freeman et al., 2008).

The households (Consumer) derive their utility by consuming cattle products and services. In this study cattle is conceptualized as an asset kept by households and whose benefits (both marketed and non-marketed), they depend on for livelihood. The degree of dependency on non-marketed benefits will be assessed through WTP as depicted by Arrow A in Figure 1. The value derived from non-marketed benefits differs among household as influenced by the households, market and animal related characteristics.

\section{Empirical model}

A Probit model was fitted to assess factors that jointly influence the probability of a "yes" response to a WTP amount for non-marketed benefits of cattle. The model assumes a normal distribution and has a binary dependent variable given that, the dependent value is 1 for those WTP for non-marketed benefits and 0 otherwise. According to Woodridge (2004), the standard Probit model can be defined as: Let $\mathrm{Y}^{*}$ be an unobserved, or latent variable, determined by:

$$
Y_{i}=Y^{*}{ }_{i}=\lambda X_{i}+\mu_{i} \text { if } Y^{*}{ }_{i}>0 \text { Otherwise, } Y_{i}=0 \text { if }\left[Y^{*}{ }_{i} \leq 0\right. \text { ] }
$$

The model assumes that random error term $\mu_{\mathrm{i}}$, is normal and independently distributed with mean of zero $(0)$, which means that $\left[1-F(-z)=(F(z)]\right.$ and constant variance $\sigma^{2}$. If the non-observed latent variable $Y_{i}^{*}$ is greater than 0 , the observed qualitative variable $Y_{i}$ which is indicative of the WTP for non-marketed benefit of cattle, takes the value of 1 . Alternatively, if $Y_{i}^{*}$ is less than or equal to $0, Y_{i}$ becomes zero implying lack of WTP for non-marketed benefits of cattle. From Equation (1) and the assumption given, we derive the response probability for $\mathrm{Y}$.

$P(Y=1 \mid X)=\left(P\left(Y^{*}>0 \mid X\right)=P(\mu>-(\beta 0+X \beta \mid X)=1-F[-\beta 0+X \beta]=F(\beta 0+X \beta)\right.$

Compared to OLS, interpreting of Probit coefficients can be complicated because ordinary output provides only a single coefficient for each independent variable despite two types of cases predicted for each independent variable in the analysis. This implies that the Probit model yields the effects of independent variable on the values of the dependent variable, when the value of $Y$ is 1 . 


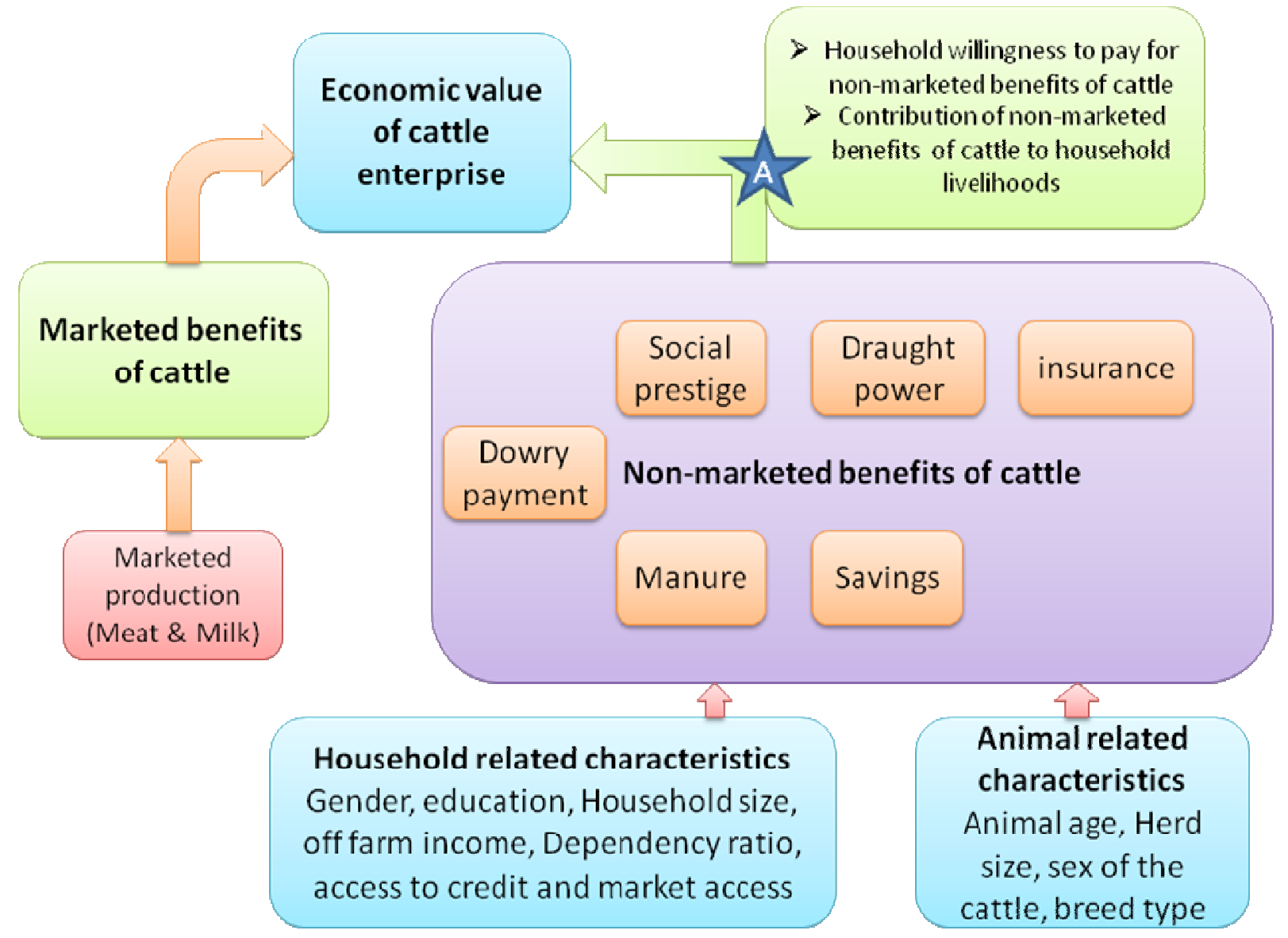

Figure 1. Conceptual framework for assessing the probability of willingness to pay for non-marketed benefits of cattle and the contribution of non-marketed benefits to the household livelihoods (Source Author, 2009).

However, for 0 values of $\mathrm{Y}$, the model yields probability of observing non-zero value of the dependent variable. Consequently, the model coefficient cannot be used directly to describe both effects, a major cause of coefficient misinterpretation by researchers (Woodridge, 2003).

However, one could use significance of the coefficients and the marginal effect on predicted probabilities by each explanatory to obtain more information (Maltsoglou and Rapsomanikis, 2005) Thus, the magnitudes of each $\beta$ 's are not, by themselves, useful (in contrast to the linear probability model). In the present study coefficients obtained from the Probit model and the marginal effect of each explanatory variable on the probability has been utilized to show effects of changing them on the probability of WTP for nonmarketed benefits of cattle.

The basic relationship to be utilized in estimating probability of WTP for non-marketed benefits of cattle is $(P(Y=1))$ and to estimate the effect of $X_{j}$ on the probability of WTP is $P(Y=1 \mid X)$. However, due to the complicated non-linear nature of $F$ (binary outcome), calculus was utilized to obtain partial effect of the independent variables on the predicted probability. Therefore, partial effect on $P(X)=P(Y=1 \mid X)$ were obtained from the partial derivative result as obtained by Woodridge (2003), given as:

$\partial \mathrm{p}(\mathrm{x}) / \mathrm{dx} \mathrm{x}_{\mathrm{j}}=f(\beta 0+x \beta) \beta_{j}$ where $f(z) \equiv(d F / d z)$

The Probit model $F$ (Binary outcome) is a strictly increasing cdf, and so $f(z)>0$ for all $Z$, since $F$ is the continuous density function (cdf) of a continuous random variable and $f$ is a probability density function. Therefore, the partial effect of $x_{j}$ on $P(x)$ depend on $X$ through the positive quantity $f(\beta+x \beta)$ which means that the partial effect always has the same sign as $\beta_{j}$.

It was hypothesized that, the probability of household WTP for the non-marketed benefits of cattle was due to the combined effect of household and cattle related characteristics. The Probit estimation model was thus specified as:

$Y_{i}=\beta_{0}+\beta_{1}$ OFFINC $+\beta_{2}$ DEPRAT $+\beta_{3}$ CATTLETYPE $+\beta_{4}$ HERDSIZE $+\beta_{5}$ CREDIT $+\beta_{6}$ FSIZE $+\beta_{7}$ GENDER $+\beta_{8}$ HSIZE $+\beta_{9}$ $D I S T M K T+\beta_{10} E D U C Y R S+\beta_{11} A N A G E+\beta_{12} A N A G E^{2}+\mu_{i}$

Otherwise $Y_{i}=0$

Where: $\beta_{0}$ is the constant term; $\beta_{1}$ to $\beta_{12}$ are the coefficients of characteristics that influence probability of household WTP, and $\mu_{i}$ are the error terms $\mathrm{D}$.

The explanatory variables considered comprised: Off-farm income (OFFINC), household dependant ratio (DEPRAT), Cattle types (CATTLETYPE), herd size (HERDSIZE), access to credit (CREDIT), Farm size (FSIZE), gender of the household head (GENDER), household size (HSIZE), distance to the market (DISTMKT), years spent on education by household head (EDUCYRS), age of the animal (ANAGE) and age of the animal squared $\left(\mathrm{ANAGE}^{2}\right)$. 
The dependent variable $Y_{i}$, is based on cattle related characteristics while the independent variables are a mixture of cattle and household level variables thus yielding independent observations across households. To circumvent dummy variable trap, cattle type was in included in the Probit model as a dummy variable with heifer as the baseline group,. To avoid the problem of biased variance of estimated parameters and to get reliable $z-$ values for the independent variable coefficients, heteroscedasticity was tested for following four steps procedure as suggested by Goldfeld-Quandt test on each of the independent variables (Gujarati, 2004). The F-value for one denominator and one numerator degrees of freedom at the $5 \%$ level is 161 . Since the estimated $F(=\lambda)$ value does not exceed the critical value, the assumption of heteroscedasticity was rejected.

The presence of multicollinearity was assessed using Mc Fadden $R^{2}\left(R^{2}{ }_{M F}\right)$. Mc Fadden and Lemma (1981) and Yazici et al. (2007) has interpreted $R^{2}$ MF as an approximate explained variation accounted for by the explanatory variable. The estimated, $R^{2}{ }_{M F}$ was found to be 0.3 and thus within the accepted range of between 0.2 and 0.4 for dichotomous models (Gujarati, 2004). In addition, z-test was also examined that the coefficients of at least some explanatory variables were statistically different from zero.

Since high bi-variate correlation among independent variable in excess of 0.8 suggest the presence of multicollinearity, pair wise correlation between all explanatory variables were examined and found not to exceed 0.65. Nonetheless, high zero-order correlations is just a sufficient but not a necessary condition for the existence of multicollinearity, because it can exist even though the zero-order or simple correlations are comparatively low, for example less than 0.5 (Gujarati, 2004). Consequently, Klein's rule of thumb was utilized by regressing auxiliary variables and $R^{2}$ MF obtained assessed against the overall regression $R^{2}$ MF of WTP for all variables. Since, the Auxiliary $R^{2}{ }_{M F}$ was found not to exceed the overall $R^{2}{ }_{M F}$, it was concluded that multicollinearity was not a serious problem.

The null hypothesis was that the probability for household WTP for NMB's of cattle is not influenced by cattle and household related characteristics. However, since the computed Wald chi-square statistics of 30.58 exceed the critical Wald chi-square value at $\mathrm{p}<0.01$, the null hypothesis that all coefficient of explanatory variable are zero except for the intercept was rejected; in favor of alternate hypothesis that at least one explanatory variable coefficient in the model is not equal to zero and thereby influences the probability of household WTP for NMB's.

\section{Study area}

The data were collected in Mabalane District Mabalane, which is in Gaza province of Mozambique. Mabalane district is situated approximately $314 \mathrm{~km}$ north of Maputo; the capital city of Mozambique. It occupies an area of $9580 \mathrm{~km}^{2}$ of which $75 \%$ is ASALs. The district has a population of 32,040 inhabitants (Government of Mozambique, 2007). The predominant activity is agriculture (both crop and livestock farming). The population density in the district is 3 people per $\mathrm{km}^{2}$, far below the national average of 25 people $\mathrm{km}^{2}$ (Government of Mozambique, 2007).

\section{Data}

Based on sample size calculation (WHO, 2005) at the $95 \%$ confidence interval, $\pm 10 \%$ precision, 184 households were sampled and surveyed. The National census, 2007 data that specified the name of district and villages was utilized in random selection of the study district and its 12 villages. In each village, 12 households were selected randomly yielding a sample of 184 households. A comprehensive dataset that comprised household demographic, household's livelihood, livestock ownership and other standard cattle related activities, were collected through a structured questionnaire.

\section{Data reliability and validity}

In order to control for data reliability, validity, measurement and sampling errors, a dozen questionnaires were field-tested among the agro-pastoralist households of Kokwe village in Mabalane districts by a team comprising the researcher and eight extension staffs. The extension staffs had adequate knowledge of the study area including field experience in data collection (as enumerators, translators, interviewers, facilitators, and field workers) in the Mabalane Gaza province. During the field-pretest, each completed questionnaire was checked by the enumerators and researcher within one day of the interview. To increase the accuracy and quality of the survey data, supervision of field staff during the actual survey was done on daily basis. The data from the questionnaire were entered into access database and checked for data entry and coding errors. Data cleaning was done in Microsoft EXCEL. Supervision and on the spot assistance during data cleaning was ensured throughout the process. Descriptive statistical analyses were carried out using STATA (release 10.0/SE) software.

\section{RESULTS AND DISCUSSION}

Table 1 present the Probit estimates for factors influencing probability of household WTP for NMB's of cattle. The result shows that bulls, cows, age of the animal (ANAGE), herd size (HERDSIZE) and indigenous breed of cattle (INDBRED) were animal related characteristics that had a significant influence on the probability of households WTP for NMB's of cattle.

The respective coefficient for each explanatory variable measures the effect of the variable on the probability of households' willingness to pay for NMB's of cattle. The cattle category cows and bull are significant and consistently positive at $p<0.001$, on explaining the probability of household WTP for NMB's of cattle, implying that farmers derive greater NMB's from cow and bulls when compared to heifer and calves. The higher NMB's derived from cow and bull can be attributed to the higher contribution they make to the household compared to heifer and calves. This could be due to fact that cows and bulls are more mature and stronger than heifer and calves hence providing higher returns.

Higher return could be for example through the provision of draught power, in which case cow and bull are more likely to work longer and more efficiently before exhaustion as compared to calves and heifer which have not developed fully to start being utilised for draught power. The importance of cattle maturity in providing NMB's to the households has been observed elsewhere in communal farming system of Zimbabwe (Barrett et al., 2001). It is therefore not surprising that results indicate that increasing the numbers of cows and bulls (by a TLUs) that a household owns, enhances the probability of household WTP for NMB's by 0.8 and $0.9 \%$, respectively. However, despite the significant influence by bull and 
Table 1. Probit estimates of the factors influencing the probability of households' willingness to pay (WTP) for nonmarketed benefits (NMB's) of cattle.

\begin{tabular}{lcccc}
\hline $\begin{array}{l}\text { Independent } \\
\text { variable }\end{array}$ & Coefficient & Standard error & $\begin{array}{c}\text { Level of } \\
\text { Significance }(\mathbf{P}>\mathbf{Z})\end{array}$ & $\begin{array}{c}\text { †Change in } \\
\text { probability }\end{array}$ \\
\hline Animal related characteristics & $0.472^{\star * *}$ & 0.120 & & \\
BULL & $0.421^{* *}$ & 0.098 & 0.000 & 0.009 \\
COWS & 0.125 & 0.092 & 0.000 & 0.008 \\
CALVES & $0.521^{* *}$ & 0.251 & 0.176 & 0.003 \\
ANAGE & $-0.24^{*}$ & 0.137 & 0.039 & 0.009 \\
ANAGE & $0.281^{* *}$ & 0.070 & 0.076 & 0.004 \\
HERDSIZE & $0.018^{*}$ & 0.010 & 0.001 & 0.005 \\
INDBRED & & & 0.076 & 0.000 \\
& 0.018 & 0.043 & & \\
Household related characteristics & 1.501 & 0.673 & 0.000 \\
FSIZE & $3.134^{* *}$ & 0.077 & 0.037 & 0.066 \\
DEPRAT & $0.200^{* *}$ & 0.450 & 0.010 & 0.004 \\
HHS & 0.211 & 0.060 & 0.638 & 0.004 \\
GENDER & 0.069 & 0.421 & 0.248 & 0.001 \\
EDUCYRS & 0.186 & 0.008 & 0.658 & 0.004 \\
CREDIT & $-0.016^{* *}$ & 0.100 & 0.050 & 0.000 \\
OFFINC & $0.09^{* *}$ & 0.033 & 0.002 \\
DISTMK & & & \\
\hline
\end{tabular}

Log Likelihood = -27.28; This is the log likelihood of the fitted model. It is used in the Wald Chi-Square test of whether all predictors' regression coefficients in the model are simultaneously zero. Number of observation $(n)=184$; Predicted probability for WTP $=0.99 ; \mathrm{H}_{0}=\hat{a}_{j}=0$, Wald $\div{ }^{2}(16)=30.58$; The number in the parentheses indicates the degrees of freedom of the Wild Chi-Square distribution used to test the Wald Chi-Square statistic; ${ }^{* *},{ }^{* *}$ and ${ }^{*}$ indicates significance level at 1,5 and $10 \%$, respectively; change in probability is the change per unit change in each of the independent variables. That is, the effect of a unit change in the dependent variable on the probability that household WTP for NMB's of cattle equal to $1 ;{ }^{\dagger}$ Change in probability given by $\beta_{j} f\left(Z_{i}\right)$, where $f\left(Z_{i}\right)$ is the density function of the standard normal variable and $Z_{i}=\beta_{1}+\beta_{2} X_{2 i}+\cdots+\beta_{k} X_{k i}$, that is, the probit regression model used in the analysis

cows on probability of household WTP for NMB's compared to heifer and calves in Mozambique. In their study Ouma et al. (2004), on assessing socio-economic benefits of cattle among smallholders' farmers in Kenya, found that bull and calves were in less demand than cows and heifer. Lack of demand for bull and heifer implied that they could be easily disposed off whenever a need arose. This indicates that the objectives of cattle keeping objectives among farmers plays a major role in determining the value attached to cattle.

Nevertheless, resources endowment also determines the systems of cattle production which in turn influences cattle keeping objectives. In Ouma et al. (2004) study in Kenya, majority of the cattle keeping households studied was smallholders dairy oriented farmers. Consequently, their cattle keeping objectives were mainly driven by the derived marketed benefits derived such as milk. As a result, bull and calves could easily be disposed off compared to cow and heifers since marketed benefits derived are low. Conversely, household studied in Mozambique mainly rears cattle in agro-pastoral system of production with main objective of deriving NMB's.

The results shows that ANAGE had a positive and significant $(p<0.05)$ influence on probability of household
WTP for NMB's of cattle, implying that the benefits derived from different cattle categories increases with age. Consequently, NMB's that can be derived from a 1 year male calf is less compared to a 2 years old heifer. To provide draught power, for example, the 2 year old oxen would be preferred to the 1 year old male calf. As a result, higher value is attached to cattle from which much NMB's is derived.

Thus, increase in animal age by one year causes the probability of household WTP for NMB's to rise by $0.9 \%$. However, the positive influence by ANAGE on the probability of household WTP cannot continue rising infinitely, but only up to a certain age when it starts declining and thereby impacting negatively on the probability of household WTP for NMB's as depicted by $\mathrm{ANAGE}^{2}$. In general therefore the contribution to the household by all NMB identified as most important objective (draught power, financing, insurance and use of cattle as a store of wealth) increases with animal age. Gilles (1991) also argues that lack of saving and other investment opportunities, leads the use of cattle as a capital investment to avoid risk.

The results also shows that herd size, had a positive and significant influence $(p<0.001)$ on the probability of 
household WTP for NMB's of cattle, implying that household with large herds of cattle derived more nonmarketed benefits of cattle relative to households with small cattle herd size. Cattle is considered as an assets, consequently with larger herds, household are more secure in terms of finance and insurance, compared to household whose herd size is small. Upton and Otte (2004) also argued that livestock ownership increases the wealth of rural household and raises the income earning potential. Therefore, household with larger herds of cattle generate more income hence lowering their vulnerability potential. Consequently, increasing the herd size by a TLU would raise the probability of household WTP for NMB's by $0.5 \%$.

Positive influence on probability for WTP by herd size could explain why household with small cattle herd would attach a lot of importance to build up of herd size. The results also indicate that INDBRED had a positive and significant $(P<0.1)$ influence on probability WTP for NMB's, implying that households perceived indigenous breed of cattle as a better asset relative to other breeds types. In Arid and semi-arid land (ASALs) indigenous breed of cattle are more suited and tolerant to diseases and insect such as Tsetse flies which are predominant in Mozambique than other cattle breeds. Indigenous breed of cattle are also well adapted for trekking long distances in search of water and pasture.

Four household related characteristics namely: Dependant ratio (DEPRAT), household size (HHS), offfarm income (OFFINC) and distance to the market (DISTMK) had significant $(p<0.05)$ influence on probability of household WTP for NMB's of cattle. However, as expected OFFINC had negative influence on probability of household WTP for NMB's of cattle. That is, households with high off-farm income tend to have low reliance on NMB's of cattle implying that households with a better access to off-farm income attached little importance on NMB's derived from cattle, at ceteris paribus. Moreover, off-farm income provides households with an alternative for offsetting expected and unexpected expenditure, while household with low access to off-farm income tend to have their cattle assume such roles as insurance and financing.

The DISTMK, had a positive and significant influence on the probability of household WTP for NMB's of cattle indicating that households located far from the market had a higher probability of WTP for NMB's of cattle. The positive and significant influence by DISTMK on probability of household WTP for NMB's could be attributed to inability to dispose cattle whenever a need arose, particularly by household far from the market due to low level market interaction. Consequently, increasing the distance of the household to the market by $1 \mathrm{~km}$ enhanced the probability of household WTP for NMB's by $0.2 \%$, implying that policy recommendation with a focus on market access is likely to have an enormous impact on the reliance on NMB's of cattle.
The DEPRAT and HHS significantly and consistently influenced the probability of household WTP for NMB's of cattle, implying that households derive greater benefits from NMB's of cattle in terms of meeting their expected and unexpected expenditures. Consequently, increasing the HHS by one person in adult equivalent raises the probability of household WTP for NMB's by $0.4 \%$.

Accordingly, DEPRAT had a positive and significant influence on the probability of household WTP for NMB's. The positive influence by DEPRAT and HHS could be attributed to fact that household with high dependency requires a good coping strategy for dealing with high risk and financial obligation, thus attaching a much importance on cattle NMB's and consequently WTP. The high importance attached to NMB's of cattle explains why, increasing DEPAT by one dependant would causes the probability of households WTP for NMB's to increase by $0.7 \%$. Household dependency ratio is therefore important in determining household reliance on nonmarket benefits of cattle as well as their WTP.

\section{Summary}

The importance attached to the NMBs of cattle and the factors influencing household willingness to pay for them were unknown. Moreover, it was not clear whether NMBs of cattle made significant contribution to household livelihoods. Consequently, this study hypothesized that, despite the importance attached to the cattle, the probability for household WTP for NMBs was not in any way influenced by neither cattle nor household related characteristics. The study also hypothesised that NMBs of cattle did not have any significant contribution to the household livelihoods. Thus attempt aimed at understanding the importance attached to NMBs of cattle, factors influencing households' WTP for them and whether they make any contribution to the household livelihood could be desirable.

Therefore this study, sought to identify the NMBs of cattle in the agro-pastoralist system and to assess the factors influencing the probability of households WTP for the NMBs of cattle in Mabalane district. The study also aimed at assessing the contribution of NMBs of cattle to the household livelihoods in agro-pastoral system of production.

A random sample of 192 household practicing agropastoral system production, were selected in Mabalane district in Gaza province of Mozambique, on March 2009. The National Census, 2007 lists were used to select the households sample. A semi structured questionnaire was then used to collect a comprehensive dataset that comprised relevant household demographic, livestock ownership and other standard cattle related activities. In addition, data on cattle and household related characteristic was hypothesized to influence the WTP for the NMBs of cattle. 
To characterize the sampled households' descriptive statistics were utilized. The NMBs derived from cattle were then identified and their relative weights determined. This enabled NMBs of the different cattle categories to be ranked according to the attached weight. A Probit regression analysis was then estimated to determine the factors influencing households WTP for the NMBs of cattle.

\section{Conclusion}

The WTP for NMBs of cattle were found to be influenced by both animal (cattle age, cattle type, breed and herd size) and household characteristics (distance to the market, household size, dependant ratio and off-farm income). Herd sizes and cattle type were some of the animal related factors that were most important in influencing household WTP. The influence emanating from cattle type could be attributed to the amount of NMBs like draught power, financing, savings and bride price, much of which are derived from indigenous compared to crosses and exotic cattle. Moreover, large herd sizes endows household with a high social status and provide them with a form of savings, insurance and financial security, thus making households less vulnerable.

Household size, dependant ratio and distance to the market were important household related characteristic that had positive influence on household WTP. The influence was largely attributed to high financial obligation associated with large household size and high dependence ratio, necessitating a need for financial security. Cattle through NMBs provide financial and insurance benefits because they are considered as an asset which could be sold to; offset financial obligation, provide investment capital as well as increase household income and hence reducing household vulnerability potential. Nevertheless, contribution of NMBs to household income varied across households.

\section{Policy recommendation}

The key finding in this study with implication for policy is that cattle have multiple uses and their non-marketed benefits plays a significant role in household livelihood. Based on these findings, it is suggested that nonmarketed benefits of cattle should not be neglected. Therefore a policy recommendation of increased marketing and sales for example a drive towards single purpose commercialized production, could well undermine non-marketed benefits derived from cattle. Specifically, the study proposes that public policies favorable to the recognition of non-marketed benefits derived from cattle are of importance in improving livelihoods among cattle keepers.

\section{REFERENCES}

Barrett CB, Reardon T, Webb P (2001). Nonfarm income diversification and household livelihood strategies in rural Africa: Concepts, dynamics, and policy implications. Food Policy 26:315-331.

Bennett J, Blamey R (2001). The Choice Modeling Approach to Environmental Valuation. Edward Elgar. Cheltenham. pp.37-69.

Bosman HG (1995). "Productivity Assessments in Small Ruminant Improvement Programmes. A Case Study of the West African Dwarf Goat". PhD. Thesis, Wageningen Agricultural University.

Bosman HG, Moll HAJ, Udo HMJ (1997). "Measuring and Interpreting the Benefits of Goat Keeping in Tropical Farm Systems". Agric. Syst. (53):349-372.

Campbell JC, Daniel W, Jane KM, Carolyn B, Doris C, Mary AC, Faye G, Nancy G, Judith M, Carolyn S, Phyllis S, Yvonne U, Susan A, Wilt DrPH, Jennifer $M, P h D$, Xiao X, Janet $S$, Victoria F, Kathryn L (2003).Risk Factors for Femicide in Abusive Relationships: Results From a Multisite Case Control Study. 93(7):1089-1097.

Carson RT, Flores NE, Meade NF (2000). Contingent Valuation: Controversies and Evidence. Environ. Resour. Econ. 19:173-210.

Dofonsou SG, Deboer LJ (2008). Ex ante non-market valuation for novel product: literature review.

Delali B (2004). Child Care among Ewe Migrants in Accra: Cases of Crisis. Research Review Supplement 16. Children at Risk in Ghana: Family Care under Review. Institute of African Studies, University of Ghana, Legon.

Doran MH, Low ARC, Kemp RL (1979). "Cattle as a Store of Wealth in Swaziland: Implications for Livestock Development and Overgrazing in Eastern and Southern Africa". Am. J. Agric. Econ. 61(1):41-46.

Dovie BDK, Shackleton CM, Witkowski ETF (2002). Direct-use values of woodland resources consumed and traded in a South African village. Int. J. Sust. Dev. World Ecol. 9(3):269-283.

Food and Agriculture Organization of the United Nations (FAO) (2007) Livestock Policy Initiative (PPLPI).

Freeman AM (1993). The Measurement of Environmental and Resource Values: Theory and Methods. Washington, DC: Resources for the Future. Bus. Econ. 491 pp.

Freeman HA, Kaitibie S, Moyo S, Perry BD (2008). Livestock, livelihoods and vulnerability in Lesotho, Malawi and Zambia: Designing Livestock Intervention for emergency situation. ILRI Research Report 8. ILRI (International Livestock Research Institute), Nairobi, Kenya. P. 62.

Gilles JL (1991). Animal Agriculture in Sub-Saharan Africa: Socioeconomic issues. Columbia, University of Missouri.

Gujarati DN (2004). Basic econometrics. Fourth edition. The McGraw-Hill Companies.

Hooton N (2000). "Demand - Led Animal Health services for Small Holder Farmers in Africa: The Potential Role of Contingent Valuation. Centre for Tropical Veterinary Medicine", MSc. Thesis. University of Edinburgh.

Just RE, Hueth DL, Schmitz A (1982), Applied Welfare Economics and Public Policy. Englewood Cliffs, NJ: Prentice-Hall.

Moll HAJ, Staal SJ, Ibrahim MNM (2001). "From Meat to Milk: Smallholders 'Livelihoods and Markets", Paper Presented at 12th Symposium Tropical Animal Health and Production, "Dairy Development in the Tropics", University of Utrecht. pp. 1-15.

Maltsoglou I, Rapsomanikis G (2005). The Contribution of Livestock to Household Income in Vietnam: A household typology based analysis.

Ouma E, Obare GA, Staal JS (2004). Cattle as asset: Assessment of Non-Marketed benefits from Cattle in smallholder Kenya crop livestock systems. Proceedings of the 25th international Conference of Agricultural Economics (IAAE) 16-22 August 2003. Durban, South Africa.

Shackleton CM, Netshiluvhi TR, Shackleton SE, Geach BS, Balance A, Fairbanks DFK (2002). Direct use values of woodland resources from three rural villages, Econ. Botany 56(2):130-146.

Shackleton CM, Shackleton SE, Cousins B (2001). The role of landbased strategies in rural livelihoods the contribution of arable production, animal husbandry and natural resource harvesting in communal areas in South Africa. Dev. Southern Afr. 18:581-604.

Slingerland M (2000). "Mixed Farming: Scope and Constraints in West African Savannah" Ph.D Thesis, Wageningen Agricultural University. 
Taylor JE (2002). Agriculture household models: Genesis, evolution and extension. Rev. Econ. Household 2003; 1(1):33-58.

Thornton PK, Reid RS, Kruska RL, Deichmann U, Leak SGA (2000). Will human population growth and land-use change control tsetse during our lifetimes? Agriculture, Ecosystems and Environment 77:227-236.
World health Organization (WHO) (2005). 'Summary Country Profile from HIV/AIDS treatment scale-Up.' December. 